\title{
Expansão agropecuária e degradação ambiental na bacia hidrográfica do rio Sepotuba - Alto Paraguai, Mato Grosso - Brasil
}

\author{
Agricultural expansion and environmental degradation \\ in the Sepotuba river basin - Upper Paraguai River \\ basin, Mato Grosso State - Brazil
}

\author{
Gustavo Roberto dos Santos Leandro ${ }^{1}$ \\ Paulo Cesar Rocha ${ }^{2}$
}

\begin{abstract}
Resumo
As diversas formas de apropriação geram importantes mudanças e impactos nas paisagens. Nesse sentido, o presente trabalho objetivou analisar a evolução espaço-temporal da expansão agropecuária, bem como os índices de degradação ambiental na bacia hidrográfica do rio Sepotuba, Alto Paraguai - Mato Grosso. Para tanto, imagens de satélite foram georreferenciadas, classificadas e processadas para o período de 19862016. Os mapas temáticos foram validados com auxílio do Índice Kappa e subsidiaram a avaliação das mudanças com o Índice de Transformação Antrópica - ITA. Os resultados mostraram que há forte relação entre a agropecuária e a supressão de importantes extensões da cobertura nativa. No alto e médio curso, Tangará da Serra como polo tem importante papel em relação às monoculturas; e no baixo curso, Cáceres exerce sua influência com a predominância da pecuária. Importantes fitofisionomias que compõem a bacia hidrográfica do rio Sepotuba foram identificadas resultado da convergência entre os biomas Amazônia, Cerrado e Pantanal. Os resultados obtidos indicam ainda diferentes graus de comprometimento da qualidade ambiental no sistema do rio Sepotuba, conforme a expansão dos usos e ocupação da terra em suas sub-bacias hidrográficas.

Palavras-chave: Uso da terra; Análise ambiental; Geotecnologias; rio Sepotuba; Mato Grosso.
\end{abstract}

\begin{abstract}
The diverse forms of appropriation, generate important changes and impacts in the landscapes. In this sense, the present work aimed to analyze the spatial-temporal evolution of agricultural expansion and environmental degradation indices in the Sepotuba River basin, Upper Paraguay basin. For this purpose, satellite images were georeferenced, classified and processed for the period 1986-2016. The thematic maps were validated with the aid of the Kappa Index and subsidized the evaluation of the changes through the Anthropic Transformation Index (ATI). The
\end{abstract}

${ }^{1}$ Programa de Pós-Graduação em Geografia, Faculdade de Ciências e Tecnologia - FCT, Universidade Estadual Paulista "Júlio de Mesquita Filho" - UNESP, Presidente Prudente, São Paulo - Brasil. gustavogeociencias@hotmail.com

${ }^{2}$ Departamento e Programa de Pós-Graduação em Geografia, Faculdade de Ciências e Tecnologia FCT, Universidade Estadual Paulista "Júlio de Mesquita Filho" - UNESP, Presidente Prudente, São Paulo - Brasil.pcrochag@gmail.com

Artigo recebido em: 19/10/2018. Aceito para publicação em: 04/10/2019. 
results showed that there are a strong relationship between agriculture and the suppression of important extensions of native coverage. In the upper and middle course, Tangará da Serra as a pole that has an important role in relation to monocultures. In the low course, Cáceres exerts its influence with the predominance of Livestock. Important phytophysiognomies that make up the Sepotuba river basin were identified - a result of the convergence between the Amazon, Cerrado and Pantanal biomes. The results obtained indicate different degrees of impairment of environmental quality in the Sepotuba River system, according to the expansion of land use and occupation in its sub-basins.

Keywords: Land use; Environmental analysis; Geotechnologies; Sepotuba river; Mato Grosso.

\section{Introdução}

As bacias hidrográficas constituem importante unidade espacial de análise tanto por sua dinâmica como por registrar os impactos associados à extração e ao uso dos recursos naturais. Ao considerarmos sua totalidade e complexidade, são eleitas para estudos ambientais - estrutura e funcionamento de seus subsistemas; avaliações e diagnósticos socioambientais - a fim de contribuir com o ordenamento territorial (CARVALHO, 2014; SOUZA, 2013).

No sudoeste de Mato Grosso, a ocupação não indígena é datada por volta do século XVIII, com a apropriação luso-espanhola (BINDANDI, 2014). Todavia, a exploração dos recursos naturais, principalmente do solo e água, foi intensificada ainda em 1970, sendo mais expressiva em meados de 1980 em razão da expansão agropecuária. Portanto, o território de Mato Grosso apresentou modificações em sua estrutura nas últimas décadas. E, por consequência, a degradação ambiental o coloca como um dos estados que mais registraram tal realidade (LORENZON, 2016).

A bacia hidrográfica do Alto rio Paraguai - BAP, atrelada à dinâmica na região administrativa, tem sido ocupada por diversas monoculturas. Logo, estudos apontam para importantes questões e impactos associados (SERIGATTO, 2006; SOUZA et al., 2012). Conforme os autores, extensas áreas nas bacias hidrográficas dos rios Bugres, Sepotuba, Cabaçal e Jauru, 
importantes afluentes da margem direita, tiveram suas coberturas vegetais substituídas, bem como trechos ao longo do próprio rio Paraguai (PESSOA et al., 2013; SOUZA et al., 2012).

Segundo estudo apontado por Neves et al. (2015), a expansão das atividades produtivas nas áreas de planalto da Bacia do Alto Paraguai tem potencial para impactar os sistemas abióticos e bióticos do Pantanal. Nessa perspectiva, pode-se destacar os trabalhos recentes desenvolvidos no âmbito do seu sistema hidrográfico. Autores como Pessoa et al. (2013), Neves et al. (2015), Lorenzon (2016), entre outros, analisaram a dinâmica de uso e ocupação da terra com importantes resultados e indicadores.

Nesse contexto, as geotecnologias, tais como o Sensoriamento Remoto e os Sistemas de Informações Geográficas (SIG), baseados em imagens orbitais, constituem um excelente instrumental para análise e quantificação do uso e cobertura da terra (PESSOA et al., 2013). Essas tecnologias podem auxiliar na definição dos níveis de conservação ou degradação em diferentes escalas espaço-temporal, sendo fundamental para o planejamento. Isso porque contribuem para a reconstituição de cenários e prognósticos.

Diante do exposto inicialmente, a bacia hidrográfica do rio Sepotuba demanda atenção quanto às formas de uso e à ocupação da terra, sobretudo pelas interações hidromorfodinâmicas em seu sistema e, por conseguinte, por sua relevante contribuição enquanto tributário da bacia hidrográfica do Alto rio Paraguai - BAP e Pantanal. Sendo assim, o presente trabalho objetiva analisar a evolução espaço-temporal da expansão agropecuária, bem como índices de degradação ambiental na bacia hidrográfica do rio Sepotuba, Alto rio Paraguai - Mato Grosso.

\section{Área de Estudo}

O Alto rio Paraguai é constituído por importantes sistemas de drenagem inseridos em áreas de Planalto. Sendo assim, alcançam o sistema 
de planícies e megaleques aluviais, com destaque para o Pantanal Norte, também conhecido como Pantanal de Cáceres. Assine et al. (2015) reforçam a importância dos sistemas de planície quando destacam que o Pantanal é uma bacia sedimentar situada no Centro-Oeste do Brasil, caracterizada pela presença de um moderno trato deposicional aluvial, bem como pela interação de vários tipos de sistemas desenvolvidos em uma das maiores e mais importantes áreas úmidas do planeta.

A bacia hidrográfica do rio Sepotuba, afluente da margem direita, abrange uma área de 9.903,98 $\mathrm{km}^{2}$. Ainda, importantes setores de seu sistema são sobrepostos pelos territórios de municípios como Tangará da Serra e Cáceres, na região Sudoeste de Mato Grosso. A drenagem principal da área encontra-se representada pelos rios Sepotubinha, Sepotuba, Maracanã, Sapo, Formoso, Jubinha, Juba e Tarumã (Figura 1).

Figura 1. Localização da bacia hidrográfica do rio Sepotuba, Alto Paraguai - Mato Grosso.

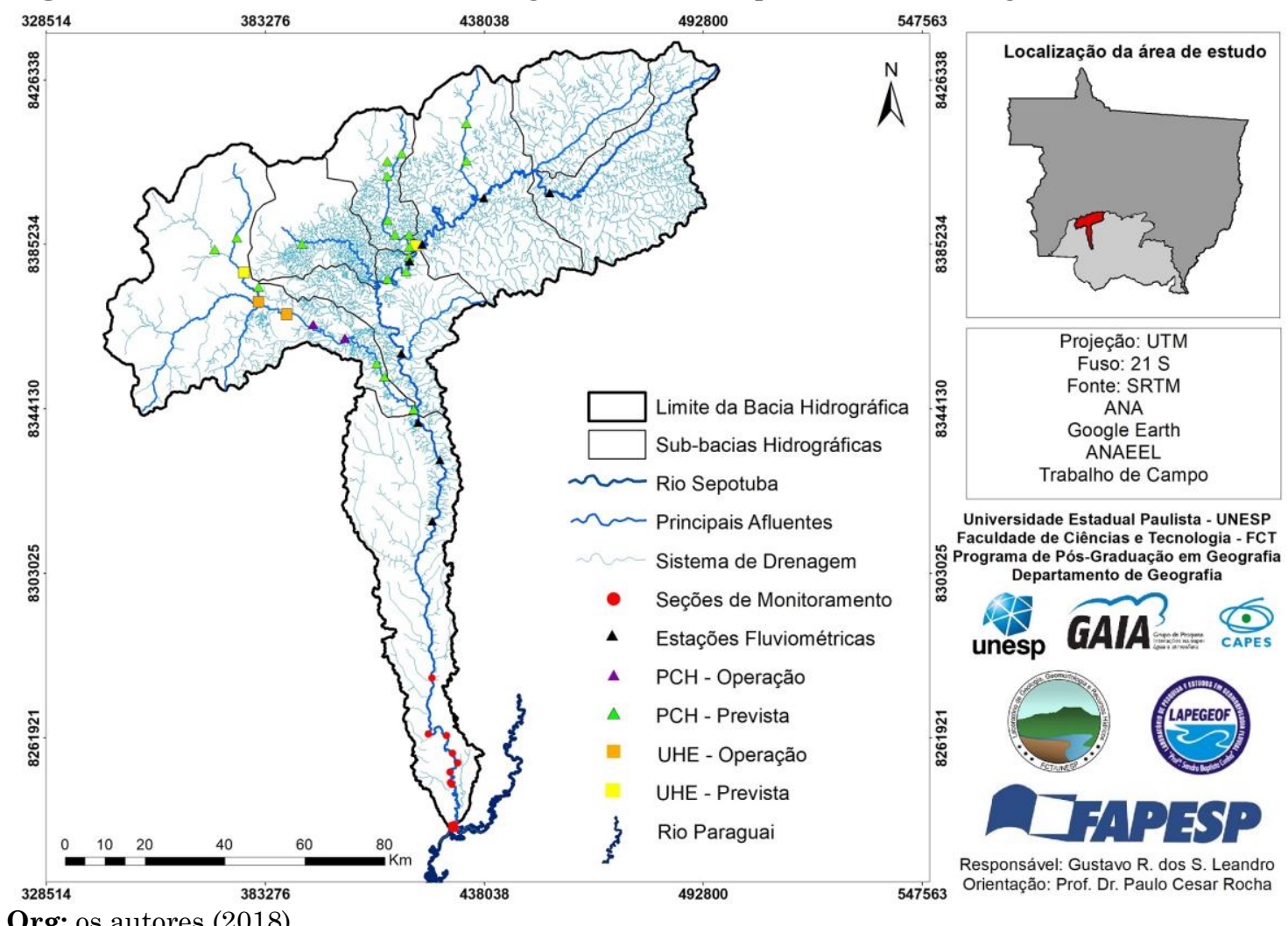

Org: os autores (2018). 
Dessa forma, a investigação da bacia hidrográfica do rio Sepotuba foi baseada no seu contexto geomorfológico entre as bordas da Chapada dos Parecis, das planícies aluviais, em sua importância fitofisionômica, considerando-se as transições entre o Cerrado e Amazônia, bem como na contribuição de seu sistema fluvial para o Pantanal (SILVA et al., 2011; SILVA et al., 2015).

\section{Procedimentos Metodológicos}

Estudos sobre as mudanças na cobertura vegetal baseiam-se, frequentemente, no método de avaliação espaço-temporal (PESSOA et. al., 2013). Como material, imagens dos satélites Landsat 5 e 8 foram utilizadas, sendo as cenas 227/70, 227/71 e 228/70 dos anos de 1986 e 2016.

Criou-se um banco de dados geográfico (BDG) no software SPRING, versão 5.2.6, do Instituo Nacional de Pesquisas Espaciais - INPE (CÂMARA et al., 1996), utilizando o sistema UTM, fuso 21S e Datum Sirgas 2000. No BDG, fez-se a importação das imagens para a composição do mosaico e seu recorte pela área de estudo (máscara).

Em seguida, realizou-se a segmentação, por meio do método de crescimento de regiões, com similaridade 100 e área de pixel 150. Fez-se coleta de amostras/treinamento, classificação supervisionada (classificador Bhattacharrya), com aceitação de 99,9\% e edição matricial/vetorial. A edição do mapeamento foi realizada no software ArcGis, versão 10.3 (ESRI, 2007), com sobreposição da composição colorida RGB das bandas 4, 5 e 6 .

A legenda das classes dos mapas de uso da terra e cobertura vegetal foi definida a partir de pesquisas no relatório técnico do Projeto de Conservação e Utilização Sustentável da Diversidade Biológica Brasileira (PROBIO) (BRASIL, 2004) e no Manual Técnico de Vegetação e Uso da Terra (IBGE 2012). Com a finalidade de verificar a confiabilidade do mapeamento gerado com auxílio dos softwares Spring 5.2.6 e ArcGis 10.3, foi 
realizada uma avaliação da exatidão, por meio do Índice Kappa, que varia de -1 a 1, e quanto mais próximo de 1, maior a precisão da classificação, conforme demonstrado na Tabela 1 (COHEN, 1960; LANDIS; KOCH, 1977; SILVA, 2003).

Tabela 1. Qualidade da classificação associada aos valores da estatística Kappa

\begin{tabular}{cc}
\hline Índice Kappa & Concordância \\
\hline$<0,00$ & Péssima \\
$0,00-0,20$ & Ruim \\
$0,20-0,40$ & Razoável \\
$0,40-0,60$ & Boa \\
$0,60-0,80$ & Muito Boa \\
$0,80-1,00$ & Excelente \\
\hline
\end{tabular}

Fonte: Adaptada de Landis e Koch (1977, p.165)

O Índice de Transformação Antrópica (ITA) foi determinado a partir das porcentagens de áreas das classes temáticas quantificadas no mapa de uso da terra e da cobertura vegetal de cada sub-bacia. O cálculo do índice foi realizado usando a fórmula: ITA $=\sum(\%$ USO X PESO $) / 100$.

Desse modo, em que: ITA = Índice de Transformação Antrópica; Uso = área em valores percentuais da classe de uso e cobertura; Peso = peso dado aos diferentes tipos de uso e cobertura quanto ao grau de alteração antrópica - varia de 1 a 10 (Tabela 2). A transposição dos valores mensurados quantitativamente para classes qualitativas ocorreu por meio de adoção do método de quartis utilizado por Cruz et al. (1998): pouco degradada $(0,00-2,50)$, regular $(2,50-5,00)$, degradada $(5,00-7,50)$ e muito degradada $(7,50$ - 10,00) (RODRIGUES et al., 2015). 
Tabela 2. Pesos atribuídos às classes temáticas de cobertura vegetal e uso da terra.

\begin{tabular}{lll}
\hline Categorias & Classes & Pesos \\
\hline \multirow{4}{*}{ Uso da terra } & Agricultura & 8,00 \\
& Influência urbana & 9,70 \\
& Pecuária & 5,50 \\
& Silvicultura & 1,00 \\
& Écotono & 1,00 \\
Cobertura vegetal & Floresta aluvial & 1,00 \\
& Floresta submontana & 2,00 \\
& Floresta terras baixas & 1,00 \\
Água & Savana arborizada & 1,00 \\
& Savana Parque & 1,00 \\
Lâminas d'águas & 2,00 \\
\hline
\end{tabular}

Fonte: os autores (2018).

Portanto, assim, constrói-se o indicador do Índice de Transformação Antrópica, atribuindo valores para cada classe de uso da terra e cobertura vegetal que contribui na transformação da paisagem, pela consulta sistemática chamada "Delphi", a qual possibilita o estabelecimento do consenso sobre como quantificar o grau de modificação da paisagem (SCHWENK; CRUZ, 2008). Entretanto, os valores apresentados neste estudo foram atribuídos pelos autores com base no conhecimento da área de estudo.

\section{Resultados e discussão}

A classificação do uso e ocupação da terra, bem como das coberturas vegetais, com representação nos mapas temáticos, tiveram sua acurácia verificada pela matriz de erros, usando-se o Índice de Concordância Kappa. Os resultados obtidos com a utilização do estimador de acerto para a classificação realizada nos anos de 1986 e 2016 são valores considerados excelentes $(K>0,8)$, indicando que a classificação alcançou o resultado esperado (Tabela 3). A confusão média registrada para o ano de 1986 ocorreu associada à transição entre o Ecótono e a Floresta Aluvial. 
Tabela 3. Resultados obtidos para a avaliação da classificação dos usos e cobertura da terra.

\begin{tabular}{cccc}
\hline Ano & Desempenho Geral & Confusão Média & Índice Kappa \\
\hline 1986 & $94,42 \%$ & $5,58 \%$ & 0,92 \\
2016 & $100 \%$ & $0 \%$ & 1,00
\end{tabular}

Org: os autores (2018).

\section{Avanço dos arranjos econômicos: papel do setor agropecuário}

O estado de Mato Grosso se consolidou economicamente como um dos carros-chefe brasileiros, com respaldo na exploração de suas terras. Desse modo, Dubreuil et al. (2005) contextualizaram a evolução da chamada "conquista pioneira", a exemplo das dinâmicas socioespaciais no centro-oeste de Mato Grosso (Figura 2). Destaca-se, portanto, a consolidação agropecuária aplicada a importantes sistemas fluviais que, anteriormente, contribuíram para a colonização não indígena na região. Para tanto, a efetivação de importantes projetos como os Planos de Incentivo - PIN "Nova Amazônia" e Polocentro foram fundamentais (DUBREUIL et al., 2005).

Figura 2. Síntese dos estágios e planos de ocupação na região sobreposta à bacia hidrográfica do rio Sepotuba, Alto Paraguai - Mato Grosso.

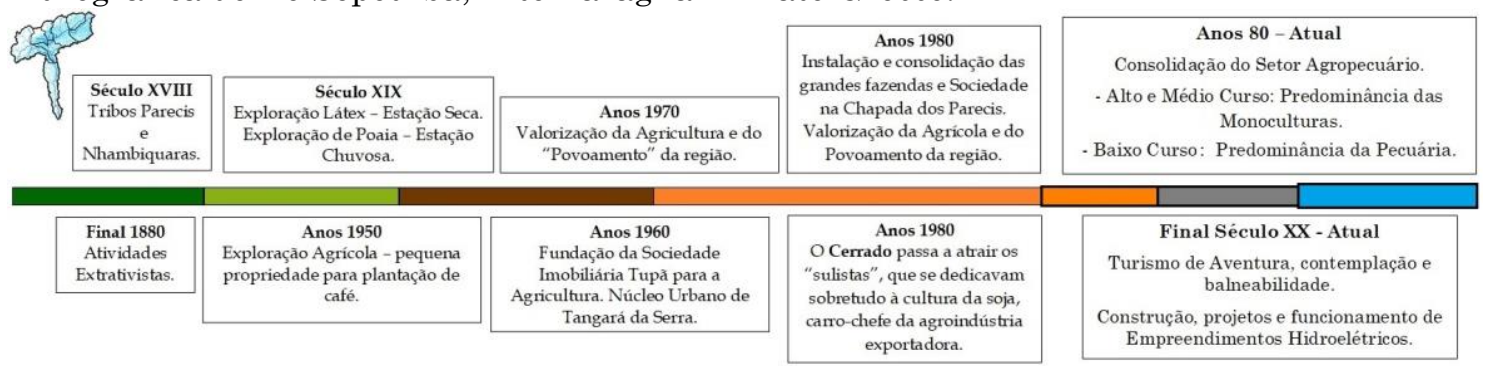

Adaptado de: Dubreuil et al. (2005).

Acrescenta-se que, por meio da análise espectral, foram identificados seis tipos de cobertura vegetal, três formas de uso e ocupação da terra, além das lâminas d'água para o ano de 1986. Ao considerar a totalidade da bacia hidrográfica do rio Sepotuba, foi possível verificar que a matriz econômica é voltada para atividades agropecuárias, principalmente em relação à extensão das áreas ocupadas pelo setor e em relação à sua expansão. 
No entanto, a introdução do uso da terra e a sua ocupação ocorreram de distintas formas, conforme os setores da bacia hidrográfica. Portanto, a segmentação de seu sistema por sub-bacias hidrográficas permitiu identificar detalhadamente cada dinâmica de uso, bem como suas particularidades.

As porções destinadas à agricultura para o ano de 1986 concentravam-se nas unidades 1 - Nascentes do Sepotuba e 3 - Médio Sepotuba (24,54\% e 39,86\%, respectivamente). Inicialmente, tal fenômeno teve relação direta com a influência de Tangará da Serra. Mais precisamente, com a locação do sítio urbano - sub-bacia 3 - Médio Sepotuba (Figura 6). De acordo com Dubreuil et al. (2005), o município tende a se firmar como polo regional concentrando os serviços essenciais. A maior parte dos grandes fazendeiros opta, respectivamente, por viver e instalar suas sedes administrativas em Tangará (DUBREUIL et al., 2005).

Ainda, foram identificadas áreas agrícolas, inicialmente fragmentadas, nas Unidades 2 e 4, inseridas em compartimentos de cabeceira entre a Chapada dos Parecis e o sistema de escarpa e, ainda, entre o Planalto de Tapirapuã (Unidade 7 - rio Tarumã), dando continuidade às áreas agrícolas da Unidade 3 (Figura 3). Conforme apontado por Dubreuil et al. (2005), as áreas de produção agrícola em Mato Grosso distribuem-se por três polos principais, sendo a região da Chapada dos Parecis uma importante produtora.

Nesse sentido, o uso e a ocupação da terra na bacia hidrográfica do rio Sepotuba apresentam papel fundamental nas transformações e nas mudanças em suas paisagens. Sendo assim, primeiramente, pela retirada da cobertura vegetal, o que pode gerar uma série de processos, como a diminuição da biodiversidade. 
Figura 3. Ocorrência das principais coberturas vegetais referente ao ano base de 1986.
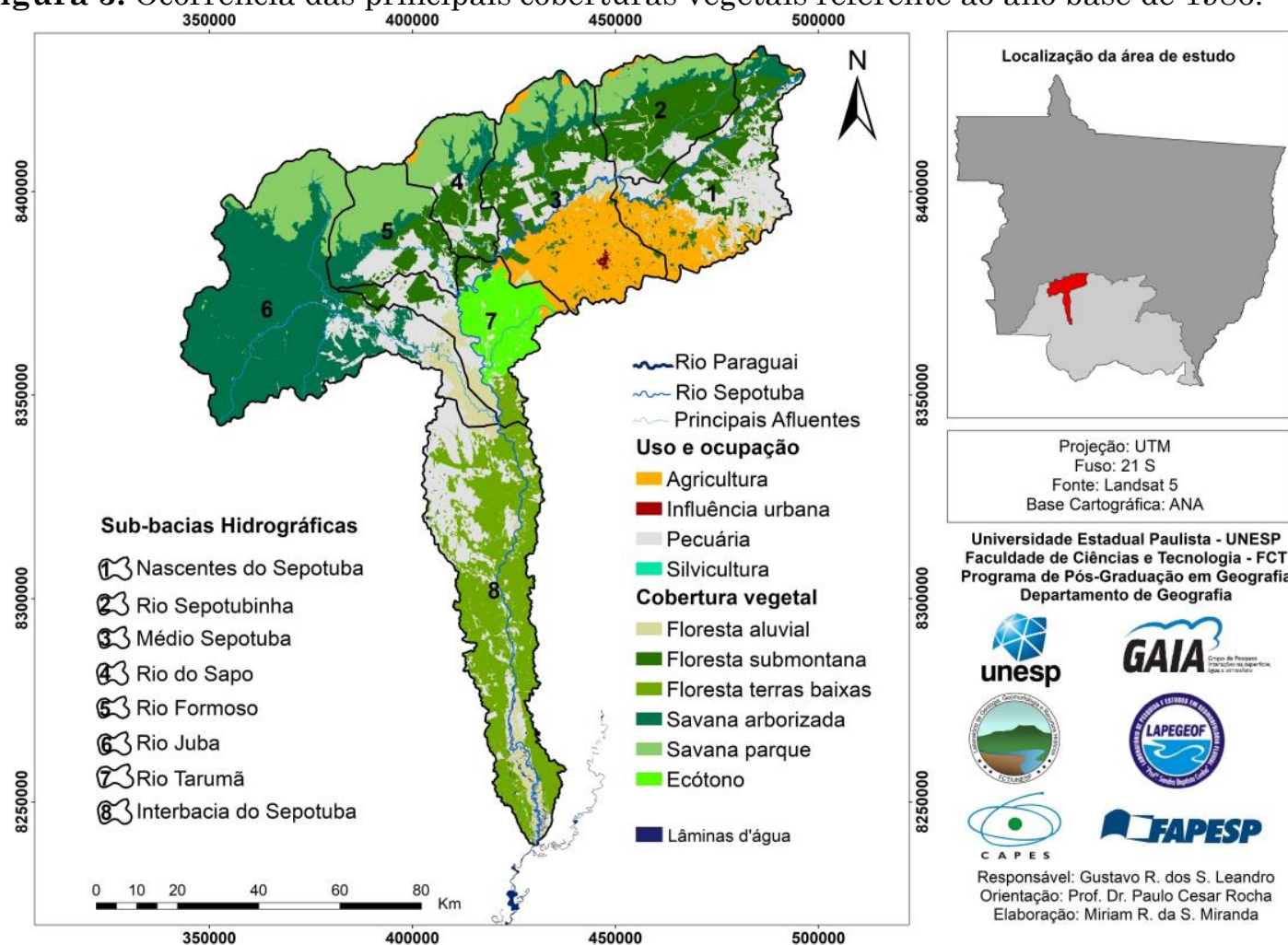

Legenda adaptada do PROBIO (2004) e IBGE (2012).

Org: os autores (2018).

Conforme Schwenk e Cruz (2008), a técnica imprópria aos solos matogrossenses, trazida pelos imigrantes da região sul e sudeste, resultou em uma resposta negativa do meio ambiente, o que levou, posteriormente, à busca do uso mais adequado, além da correção dos solos. Ainda, ao transformar o solo pobre em solo produtivo, aliado ao baixo preço das terras, houve avanço acelerado na produção de soja altamente tecnificada nas vastas terras planas do Planalto e da Chapada dos Parecis.

No ano de 2016, fica evidente o domínio agropecuário na região e as importantes alterações na cobertura vegetal (Figura 4). Como consequência, extensas áreas foram desmatadas para a introdução de pastagem e agricultura, ampliando o domínio monocultor. Pode-se dizer que, na bacia do Alto rio Paraguai, as relações econômicas ancoradas em sua agropecuária registraram, por meio de vários estudos, um avanço nas últimas três décadas. Todavia, a Silvicultura passa a compor as formas de uso e de 
ocupação da terra na bacia do rio Sepotuba (Unidade 7).

Figura 4. Principais classes de uso e cobertura atual referente ao ano base de 2016, denotando a expansão das áreas ocupadas, assim, consequentemente, redução das formações naturais.

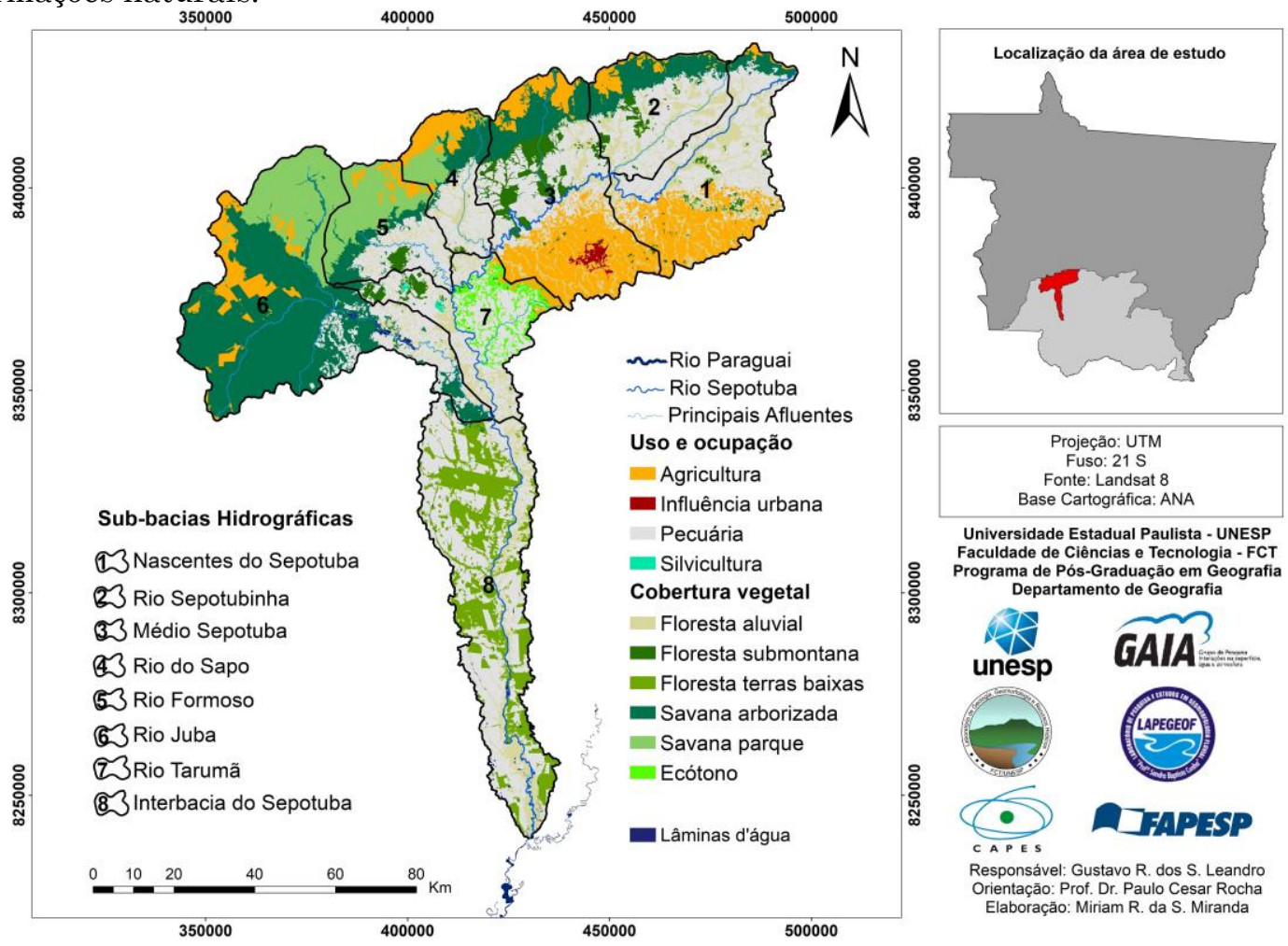

Legenda adaptada do PROBIO (2004) e IBGE (2012).

Org: os autores (2018).

No alto curso do rio Sepotuba, sobretudo nos compartimentos da Chapada e do Planalto dos Parecis, observa-se a predominância da atividade agropecuária. No entanto, fica nítida a distinção da agricultura na Chapada e, a pecuária no Planalto. Farias (2012) destacou que, quanto ao uso e à ocupação presente na bacia do Sapo - afluente da margem direita do rio Sepotuba, é possível verificar grande destaque para a atividade agropecuária. De modo geral, pode-se observar que no contexto do uso agropecuário, a criação de gado constitui a principal atividade econômica, especialmente por meio da criação por sistema extensivo, que utiliza o pasto como principal alimento.

Portanto, além das monoculturas, o setor Pecuário ocorre em todas as 
subunidades. As áreas destinadas à pastagem ocorreram principalmente em seu eixo central com destaque para o médio e baixo curso dos afluentes. Portanto, o uso pecuário nos anos de 1980 já era presente, intensificando-se em importantes compartimentos morfológicos. Nesse caso, cabe ainda uma maior atenção para as Unidades 1 e 2 - cabeceira de drenagem, bem como para as áreas de transição - Ecótono na Unidade 7, tendo em vista que mais de $55 \%$ de sua área foi convertida em pastagem (Figuras 5 e 6).

Figura 5. agricultura. 1 - Nascentes do Sepotuba; 2 - Rio Sepotubinha; 3 - Médio Sepotuba; 4 - Rio do Sapo; 5 - Rio Formoso; 6 - Rio Juba; 7 - Rio Tarumã e 8 - Interbacia do Sepotuba.

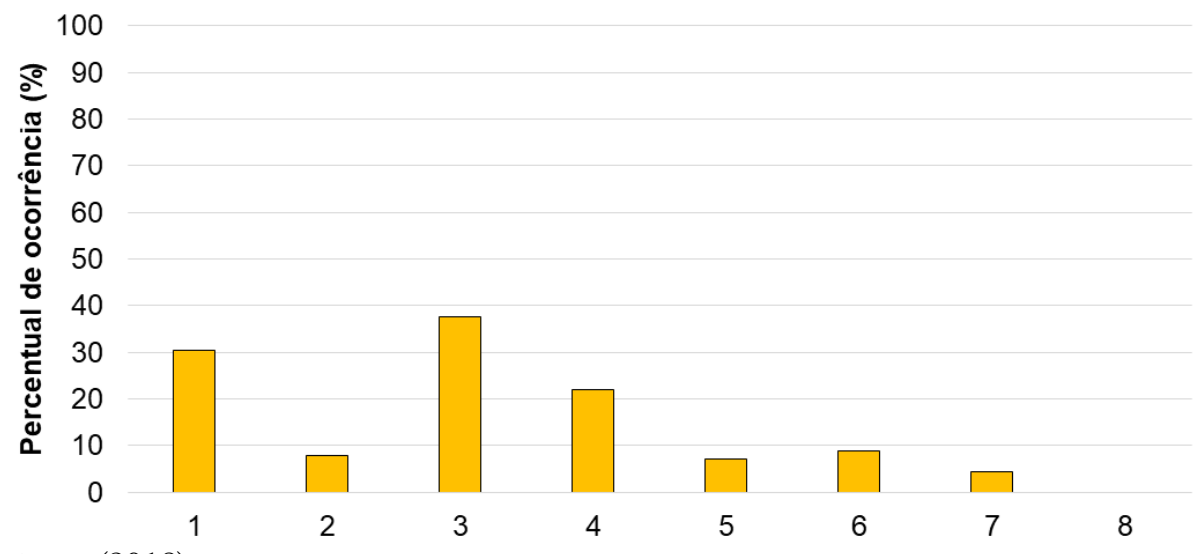

Org: os autores (2018).

Figura 6. Ocorrência de pecuária por sub-bacia hidrográfica em 2016. 1 - Nascentes do Sepotuba; 2 - Rio Sepotubinha; 3 - Médio Sepotuba; 4 - Rio do Sapo; 5 - Rio Formoso; 6 - Rio Juba; 7 - Rio Tarumã e 8 - Interbacia do Sepotuba.

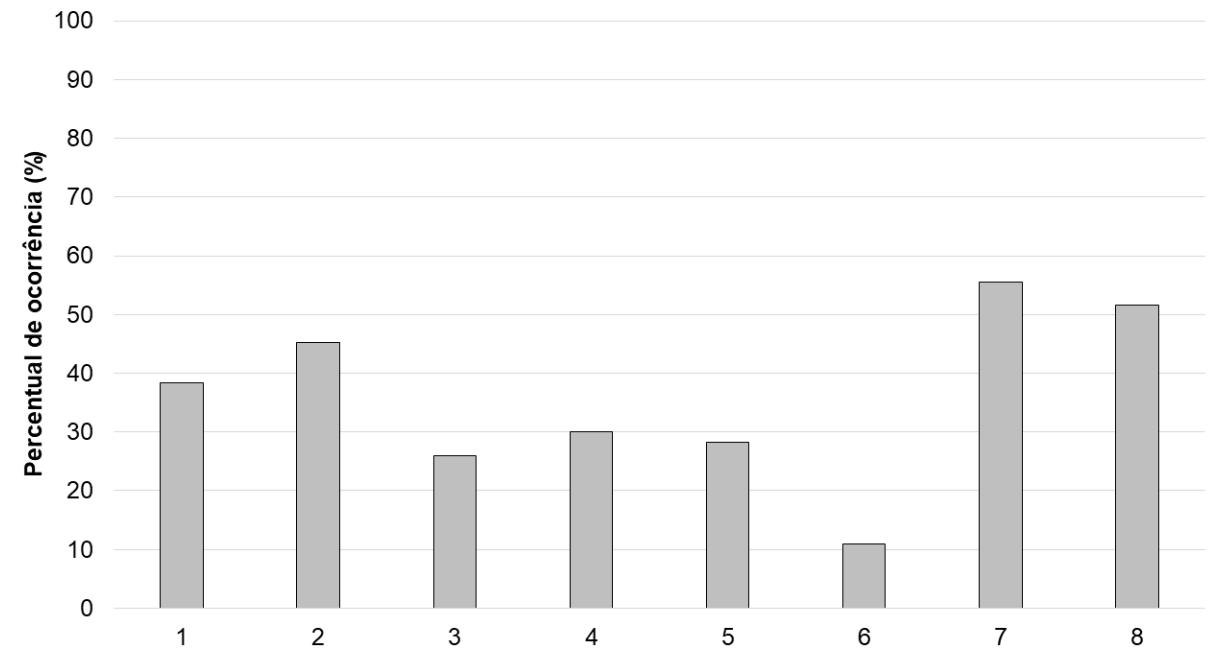

Org: os autores (2018). 
Conforme Abdon et al. (2007), no Pantanal a atividade predominante é a pecuária de corte (cria e recria) extensiva com mais de três milhões de cabeças de gado, cuja base de alimentação é a pastagem nativa. Sendo assim, Cáceres tem importante papel em relação ao setor (MIRANDA et al., 2018; SILVA et al., 2011). Destacamos, portanto, a relação entre o avanço das pastagens e do gado no baixo curso do rio Sepotuba, considerando-se a influência municipal, do ponto de vista territorial, conforme mencionado na Unidade 8, bem como do ponto de vista econômico. Miranda et al. (2018) identificaram crescimento do setor na ordem de $29,44 \%$, no período de 2003 a 2013, no município.

O munícipio de Cáceres, o mais antigo da região, fundado no século XVIII, não só apresenta o maior rebanho bovino regional do Estado como ocupa a quarta posição no ranking nacional. As características de seu quadro natural apontam a pecuária como inerente ao cenário produtivo e, por conseguinte, ao conjunto socioeconômico da região. Isso posiciona a pecuária bovina como um elemento importante dentro das chamadas "vocações regionais" de Mato Grosso (FERREIRA, 2017; SOARES et al. 2017).

Ainda, conforme Soares et al. (2017), a topografia do relevo, bem como a abundância de água e as pastagens naturais das grandes planícies contribuíram para o desenvolvimento da pecuária como atividade econômica, responsável por uma larga parcela do Produto Interno Bruto PIB municipal. Em relação à arrecadação, Cáceres possui duas principais fontes: Serviços e Pecuária. Salientando-se que a primeira está relacionada diretamente com a segunda.

Associado ao uso pecuário, impactos negativos foram identificados, sobretudo no baixo curso - Unidade 8. Em relação ao canal principal, os processos erosivos ocorrem de forma natural, no entanto, em vários pontos houve a intensificação da erosão marginal associada ao acesso e pisoteio do gado, conforme verificação de campo. Miranda et al. (2018) destacaram 
ainda o papel das queimadas como práticas de manejo do solo com influências na cobertura vegetal das Florestas e Cerrados com ocorrência nos compartimentos dos Terraços Fluviais do rio Sepotuba.

\section{Os impactos do modelo produtivo atual}

A utilização de indicadores é de grande importância, pois são instrumentos valiosos na análise de informações sobre o ambiente. Ainda, colaboram para a execução da estruturação do território (PÉREZ; CARVALHO, 2012). Portanto, conforme os autores, as abordagens de planejamento e gestão que utilizam a bacia hidrográfica como unidade básica são mais adequadas para a compatibilização da produção com a preservação ambiental.

Nesse contexto, Lorenzon (2016) avaliou a relação entre a dinâmica de uso e o nível de degradação na bacia hidrográfica do rio Cabaçal, afluente vizinho ao rio Sepotuba. Conforme a autora, em 1984, a bacia apresentava estado Regular, tendo avançado para Degradada em algumas de suas subbacias. Ainda, torna-se preocupante a previsão para até o final deste século. Caso não sejam tomadas algumas medidas de recuperação e de fiscalização, o sistema do rio Cabaçal alcançará o estado de Degradado (LORENZON, 2016).

Em relação ao rio Sepotuba, a partir do Índice de Transformação Antrópica - ITA, diferentes estágios de apropriação, conforme as condições de cada sub-bacia, foram identificados. Das oito unidades mapeadas, seis apresentaram mudança de classe em relação ao período entre 1986-2016. Na avaliação referente ao uso da terra, de 1986, seis sub-bacias foram classificadas como Pouco Degradada, condição diferente da identificada por Lorenzon (2016) para o rio Cabaçal. Cabe salientar que, dessas, quatro são áreas formadoras de importantes afluentes.

Todavia, as Unidades 1 - Nascentes do Sepotuba e 3 - Médio 
Sepotuba, para este ano, já apresentavam condição Regular devido ao intenso uso agrícola em suas sub-bacias (Figura 7). Relembramos as mudanças em relação às estruturas de pequena para média e grandes propriedades monocultoras, bem como o papel de Tangará da Serra no processo de apropriação.

Figura 7. Índice de Transformação Antrópica referente ao mapeamento do uso e cobertura da terra de 1986, bacia hidrográfica do rio Sepotuba, Alto Paraguai - Mato Grosso.

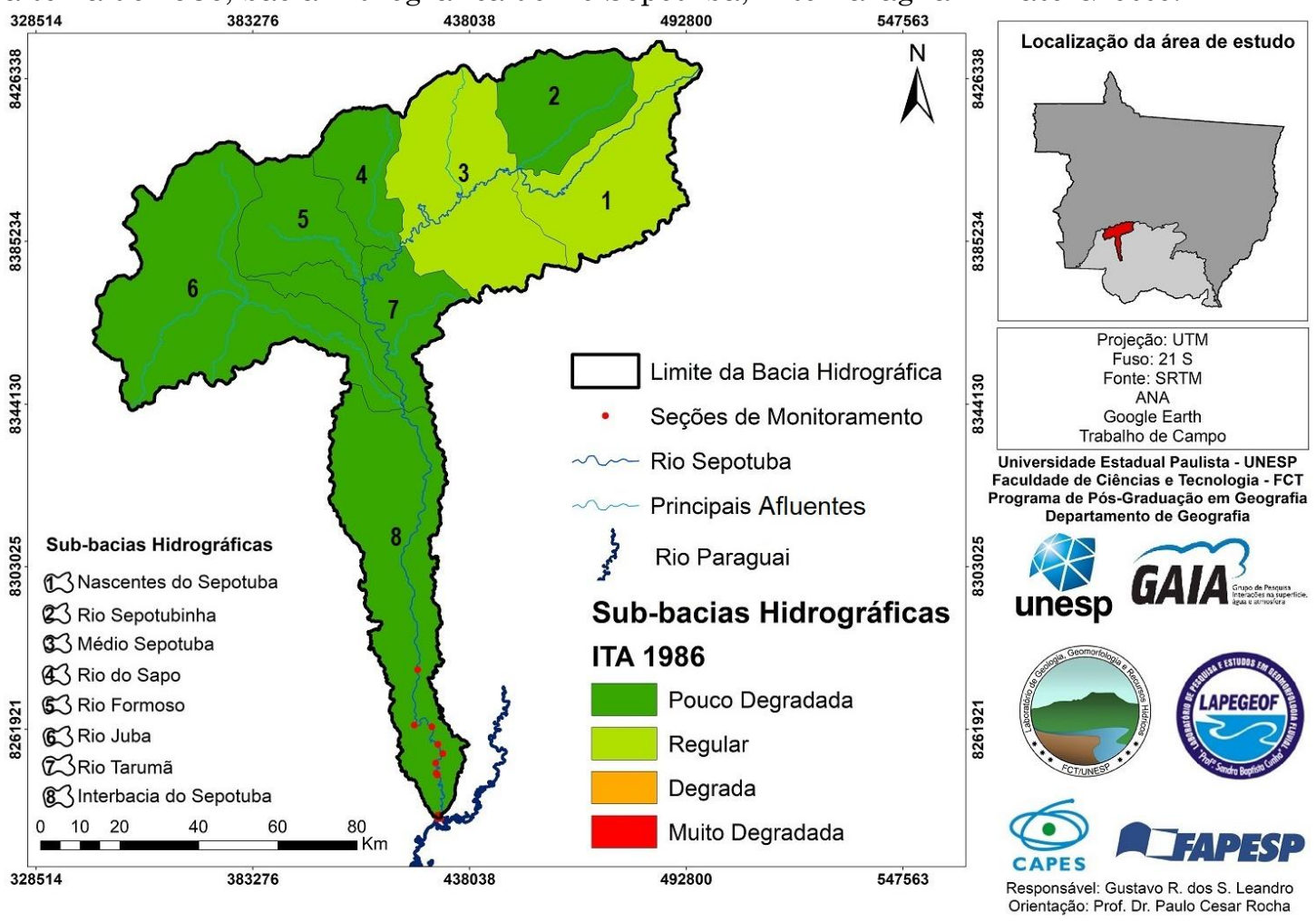

Org: os autores (2018).

Em relação ao ano de 2016, verifica-se que a única unidade ainda classificada como Pouco Degradada foi a Unidade 6 - correspondente à subbacia hidrográfica do rio Juba. Salientamos ainda que esta foi a única a não apresentar mudança em relação ao Índice obtido em 1986.

Contudo, é preciso observar a proximidade dos valores e a possível mudança de classificação conforme a intensificação do uso e a ocupação da terra em detrimento da cobertura vegetal. A Unidade 1, que corresponde a Nascentes do Sepotuba, por exemplo, apresentou valor de 4,84 para o ano de 
2016. Sendo assim, passível de mudança para a classe Degradada (valores entre 5,00-7,50) quando se relaciona ao elevado índice de uso da terra, com mais de 68\% de sua área ocupada pela Pecuária e Agricultura. Também, sua sub-bacia hidrográfica precisa ser considerada pelo fato de apresentar o maior percentual da classe Floresta Aluvial (mais de $24 \%$ para o ano de 2016). Portanto, verifica-se a importância de planos de recuperação e de conservação da unidade (Figura 8).

Figura 8. Mudança no Índice de Transformação Antrópica referente ao mapeamento do uso e cobertura da terra de 2016, bacia hidrográfica do rio Sepotuba, Alto Paraguai - Mato Grosso.

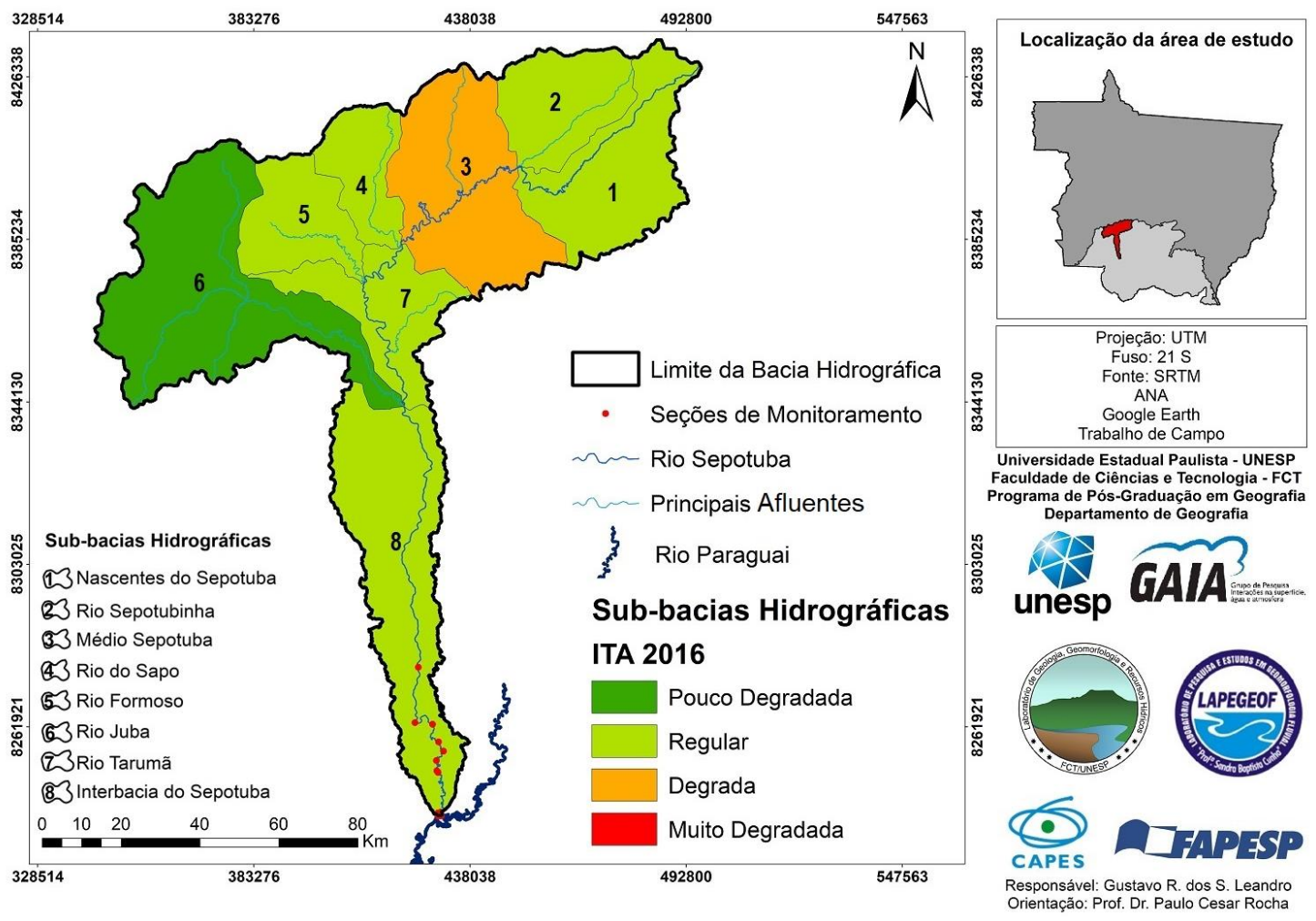

Org: os autores (2018).

Ainda em relação ao ITA - 2016, fica evidente o papel do avanço do uso na Unidade 3 - Médio Sepotuba - mudança de Regular para Degradada. Estudos realizados em importantes afluentes que drenam essa unidade corroboram para a relação entre os usos da terra e a mudança de classe. Gouveia et al. (2013) constataram que mais de 80\% da bacia do córrego do Bezerro Vermelho apresentou estado de antropização ainda em 2011. No 
trabalho realizado por Rodrigues et al. (2015), o rio Queima-Pé também apresentou condição similar com variação de Regular-Degradada.

$\mathrm{Na}$ Unidade 8, Interbacia do rio Sepotuba, as principais coberturas vegetais são associadas aos ambientes deposicionais, como Terraços Fluviais e Planície de Inundação. Conforme o Índice de Transformação Antrópica, a respectiva unidade foi classificada como Regular. Destaca-se que o indicador com maior peso é a Agricultura (8 pontos), atividade econômica não desenvolvida nessa unidade em razão de fatores associados à dinâmica de inundação. No entanto, a segunda atividade com maior representatividade é a principal forma de uso na unidade, pois a pecuária é responsável pela ocupação de mais de 50\% na interbacia do rio Sepotuba (Tabela 4).

$\mathrm{Na}$ tabela 4, é possível observar o aumento em área da Floresta Aluvial - Fa, processo inverso quando considerada a dinâmica de redução nas demais coberturas vegetais, bem como da Savana Arborizada - Sa em algumas unidades da bacia hidrográfica. De fato, sua sucessão pode ter relação com transições de uso ou, ainda, com o avanço de espécies pioneiras sobre depósitos de sedimentos ao considerarmos sua ocorrência ao longo dos canais fluviais. Outra importante mudança na paisagem está relacionada à ocorrência de lâminas d'água. Nas Unidades 4, 5 e 6 ocorreu o aumento em área. Contudo, o mesmo tem associação com a prática de reservação e não por disponibilidade natural. Em contrapartida, processo inverso ocorreu nas demais unidades, com importante redução, principalmente na Unidade 8, em que a dinâmica entre o canal e a planície de inundação é marcante.

De forma geral, a principal atividade econômica na bacia hidrográfica do rio Sepotuba é a Pecuária, seguida da Agricultura, em 1986 e em 2016, com exceção da Unidade 3 - Médio Sepotuba. Na Unidade 7, rio Tarumã, o setor é responsável pela ocupação de mais de 55\% de sua área, conforme apontado anteriormente. Portanto, mesmo com menor pontuação (Índice de Transformação Antrópica), a Pecuária tem importante papel em relação à dinâmica de uso e à ocupação nas Unidades 7 e 8. Sendo assim, é 
imprescindível a recuperação e a manutenção da cobertura vegetal em todas as unidades, sobretudo pelo importante papel que esta desempenha na conservação dos canais fluviais e Recursos Hídricos (irrigação, dessedentação animal e produção hidroelétrica).

Tabela 4. Mudanças na Paisagem com perdas e acúmulos por unidades (sub-bacias) para o período $1986-2016$.

\begin{tabular}{|c|c|c|c|c|c|c|c|c|c|}
\hline $\begin{array}{c}\text { Classes } \\
\text { Km}^{2}\end{array}$ & 1 & 2 & 3 & 4 & 5 & 6 & 7 & 8 & $\begin{array}{c}\text { Balanço } \\
30 \text { anos }\end{array}$ \\
\hline \multicolumn{10}{|c|}{ Uso e ocupação da terra } \\
\hline $\mathrm{Ag}$ & $+73,78$ & $+48,80$ & $-33,61$ & $+112,46$ & $+50,08$ & $+201,86$ & $-0,01$ & 0 & Aumento \\
\hline Ap & $+18,14$ & $+276,18$ & $+224,16$ & $+87,13$ & $+40,93$ & $+16,17$ & $+282,54$ & $+445,59$ & Aumento \\
\hline $\mathrm{Sc}$ & 0 & 0 & 0 & 0 & 0 & 0 & $+6,53$ & 0 & Recuperação \\
\hline $\mathrm{Iu}$ & $+0,02$ & $+0,16$ & $+27,63$ & 0 & 0 & 0 & 0 & 0 & Aumento \\
\hline \multicolumn{10}{|c|}{ Coberturas vegetais e água } \\
\hline $\mathrm{Fa}$ & $+260,44$ & $+118,90$ & $+104,80$ & $+48,64$ & $+40,49$ & $-59,55$ & $+48,11$ & $+86,33$ & Sucessão \\
\hline $\mathrm{Cs}$ & $-330,73$ & $-384,06$ & $-197,43$ & $-139,14$ & $-101,73$ & $-17,79$ & $-59,54$ & 0 & Redução \\
\hline $\mathrm{Fb}$ & 0 & 0 & 0 & 0 & 0 & $+0,29$ & $-65,93$ & $-533,49$ & Redução \\
\hline $\mathrm{Sa}$ & $-12,79$ & $+133,75$ & $+81,59$ & $+34,62$ & $-17,90$ & $-256,33$ & $+9,88$ & $+9,99$ & + Redução \\
\hline $\mathrm{Sp}$ & $-7,72$ & $-193,67$ & $-198,48$ & $-144,48$ & $-12,24$ & $+101,62$ & 0 & 0 & Redução \\
\hline Ecótono & 0 & 0 & $-7,43$ & 0 & 0 & 0 & $-221,15$ & 0 & Redução \\
\hline Água & $-0,27$ & 0 & $-1,00$ & $+0,76$ & $+0,37$ & $+13,88$ & $-0,42$ & $-7,94$ & Aumento \\
\hline
\end{tabular}

(1) Ag: Agricultura; Ap: Pecuária; Sc: Silvicultura; Iu: Influência urbana; Fa: Floresta aluvial; Cs: Floresta estacional decidual sub-montana; Fb: Floresta Terras Baixas; Sa: Savana arborizada; Sp: Savana parque (PROBIO, 2004; IBGE, 2012).

Org: os autores (2018).

\section{Considerações Finais}

Os dados obtidos pelo presente estudo demonstram que o uso e cobertura são uma importante variável a ser considerada para o planejamento territorial, pois incorporam importantes setores da bacia hidrográfica do rio Sepotuba - áreas de nascente e canal-planície de inundação.

Evidencia-se que as transformações na bacia hidrográfica do rio Sepotuba se intensificaram nos últimos trinta anos, ao comparar com períodos anteriores. O recorte temporal foi marcado pelos seguintes períodos: 1970-1980 com a colonização, sobretudo sulista; 1980-1990 com intensificação e avanço dos usos, associado a mudanças na cobertura vegetal; 1990 - atual aumento da produção de grãos e do rebanho bovino, bem como início dos projetos voltados ao setor hidrelétrico (anos 2000).

Os municípios de Cáceres e Tangará da Serra assumem importante 
papel quando consideramos as formas de uso na bacia hidrográfica do rio Sepotuba. O primeiro ganha destaque pelo setor Pecuário e seu avanço sobre o baixo curso da bacia do rio Sepotuba. Enquanto o segundo é considerado importante pilar do setor monocultor nos setores alto e médio curso. Nesse sentido, o papel de polo regional dos dois municípios influenciam diretamente na dinâmica econômica e nas formas de uso da terra.

Os aspectos ambientais como tipos de solo e unidades morfológicas da área pré-indicam sua fragilidade às intervenções humanas. $\mathrm{O}$ uso do Índice de Transformação Antrópica permitiu a qualificação das níveis de degradação ambiental na bacia hidrográfica do rio Sepotuba, a partir dos usos e cobertura da terra identificados anteriormente. Desse modo, a aplicação da metodologia evidenciou mudanças em seis das oito sub-bacias analisadas.

Portanto, todas as sub-bacias apresentam níveis preocupantes de mudanças, mesmo a Unidade 6 - rio Juba, classificada como Pouco Degradada, devido ao Complexo Hidrelétrico já instalado em seu sistema. Nesse sentido, a prevenção e a recuperação devem ser consideradas na intenção de evitar maiores impactos ou, ainda, a transferência deles com a produção de sedimentos para jusante.

\section{Agradecimentos}

A Fundação de Amparo à Pesquisa do Estado de São Paulo - FAPESP pela concessão de bolsa de Doutorado processo no 2016/07635-0. Também aos Laboratórios de Pesquisa e Estudos em Geomorfologia Fluvial LAPEGEOF da Universidade do Estado de Mato Grosso - UNEMAT e Laboratório de Geologia, Geomorfologia e Recursos Hídricos - Lab GGRH da Faculdade de Ciências e Tecnologia - FCT da Universidade Estadual Paulista - UNESP pelo apoio logístico e institucional. 


\section{Referências}

ABDON, M. M. et al. Desmatamento no bioma Pantanal até o ano 2002: relações com a fitofisionomia e limites municipais. Revista Brasileira de Cartografia, v. 1, n. 59, p. 17 24, 2007.

ASSINE, M. L. et al. The Quaternary alluvial systems tract of the Pantanal Basin, Brazil. Brazilian Journal of Geology, v. 45, n. 3, p. 475-489, 2015. https://doi.org/10.1590/2317$\underline{4889201520150014}$

BINDANDI, N. M. Evolução da navegação, morfologia e sedimentação no rio Paraguai no município de Cáceres, Mato Grosso, Brasil. 125 f. 2014. Dissertação (Mestrado em Ciências Ambientais). Universidade do Estado de Mato Grosso, Cáceres, 2014.

BRASIL. Projeto Probio. Avaliação e ações para a conservação da biodiversidade nos biomas Cerrado e Pantanal. Ministério do Meio Ambiente, 2004.

CÂMARA, G. Integrating Remote Sensing and GIS by Object-Oriented Data Modelling. Computers and Graphics, v. 15, n. 6, p. 13-22, 1996.

CARVALHO, R. G. As bacias hidrográficas enquanto unidades de planejamento e zoneamento ambiental no Brasil. Caderno Prudentino de Geografia. v. Especial, n. 36, p. 36-43, 2014.

COHEN, J. A. Coefficient of agreement for nominal scales. Educational and Psychological Measurement, v.20, n.1, p.37-46, 1960. https://doi.org/10.1177/001316446002000104

DUBREUIL, V. et al. Evolução da fronteira agrícola no centro-oeste de Mato Grosso: municípios de Tangará da Serra, Campo Novo do Parecis e Diamantino. Cadernos de Ciência \& Tecnologia, Brasília, v. 22, n. 2, p. 463-478, maio/ago. 2005.

FARIA, T. O. Estudo dos processos erosivos com aplicação de abordagem morfopedológica na sub-bacia do rio do Sapo, sudoeste de Mato Grosso. 2012. 164 f. Dissertação (Mestrado em Recursos Hídricos) - Instituto de Ciências Exatas e da Terra, Universidade Federal de Mato Grosso - UFMT, Cuiabá - MT, 2012.

FERREIRA, E. Cáceres: histórico, desmembramentos e a questão regional do sudoeste mato-grossense. Ciência Geográfica, Bauru, v. 21, n. 1, p. 222-238, 2017.

GOUVEIA, R. G. L.; GALVANIN, E. A. S.; NEVES, S. M. A. S. Aplicação do Índice de Transformação Antrópica na análise multitemporal da bacia do córrego do Bezerro Vermelho em Tangará da Serra - MT. Revista Árvore, n. 37, p. 1045-1054, 2013. https://doi.org/10.1590/S0100-67622013000600006

IBGE. Instituto Brasileiro de Geografia e Estatística. Manual técnico da vegetação brasileira. 3 ed. Rio de Janeiro: IBGE, 2012. 92 p.

LANDIS, J. R., KOCK, G. G. The measurement of observer agreement for categorical data. Biometrics, v. 31, n. 1, p. 159-174, 1977. https://doi.org/10.2307/2529310

LORENZON, T. H. Dinâmica do uso da terra e as implicações na cobertura vegetal, na qualidade da água e no solo da bacia hidrográfica do Cabaçal, Mato Grosso Brasil. 2016. 131f. Dissertação (Mestrado em Ambientes e Sistemas de Produção Agrícolas), Universidade do Estado de Mato Grosso - UNEMAT, Tangará da Serra - MT, 2016.

MIRANDA, M. R. S. et al. Distribuição de queimadas e mudanças na cobertura vegetal e uso da terra no bioma Pantanal, Cáceres-Brasil. Caminhos de Geografia, Uberlândia, v. 19, n. 65, p. 91-108, 2018. https://doi.org/10.14393/RCG196508

NEVES, S. M. A. S. et al. Geotechnologies applied to the evaluation of sugarcane dynamics in the Bugres river basin, Mato Grosso State - Brazil. Geografia (Rio Claro). V. 40, n. especial, p. 195-209, 2015. 
PÉREZ, D. J.; CARVALHO, S. L. Aplicação de dois indicadores ambientais para quantificação da antropização na microbacia do córrego do Ipê (SP) - Brasil. Revista de Ciências Agrícolas, v. 29, n. 2, p. 93 - 107, 2012.

PESSOA, S. P. M. et al. Análise espaço-temporal da cobertura vegetal e uso da terra na interbacia do rio Paraguai médio - MT, Brasil. Revista Árvore. v. 37, n. 1, p. 119-128, 2013. https://doi.org/10.1590/S0100-67622013000100013

RODRIGUES, L. C. et al. Dinâmica da antropização da paisagem das sub-bacias do rio Queima Pé, Mato Grosso - Brasil. Revista Espacios, n. 36, p. 5-13, 2015.

SCHWENK, L. M.; CRUZ, C. B. M. Conflitos socioeconômicoambientais relativos ao avanço do cultivo da soja em áreas de influência dos eixos de integração e desenvolvimento no Estado de Mato Grosso. Acta Sci. Agron., v. 30, n. 4, p. 501-511, 2008. https://doi.org/10.4025/actasciagron.v30i4.5305

SERIGATTO, E. M. Delimitação automática das áreas de preservação permanente e identificação dos conflitos de uso da terra na bacia hidrográfica do rio Sepotuba - MT. 2006. 203f. Tese (Doutorado em Ciência Florestal) - Universidade Federal de Viçosa - UFV, Viçosa, 2006.

SILVA, A. de B. Sistemas de Informações Geo-referenciadas: conceitos e fundamentos. São Paulo: Unicamp, 2003. 236 p.

SILVA, C. J. et al. Biodiversity and its drivers and pressures of change in the wetlands of the Upper Paraguay-Guapore Ecotone, Mato Grosso (Brazil). Land Use Policy, 47, p. 163178, 2015. https://doi.org/10.1016/j.landusepol.2015.04.004

SILVA, J. S. V. et al. Evolution of deforestation in the brazilian Pantanal and surroundings in the timeframe 1976 - 2008. Geografia, Rio Claro, v. 36, número especial, 35-55, 2011.

SOARES, J. C. O.; SANTOS, L.; CALDAS, J. A. P. A pecuária bovina no município de Cáceres-MT: reflexos no contexto socioeconômico. Ciência Geográfica, Bauru, v. 21, n. 1, p. 184-197, 2017.

SOUZA, C. A.; PIERANGELI, M. A. P.; SOUSA, J. B. Análise espaço-temporal do corredor fluvial do rio Paraguai no trecho entre Cáceres e a ilha Taiamã/MT. Revista Brasileira de Cartografia, v. 65, n. 4, p. 551-564, 2012.

SOUZA, J. O. P. Dos sistemas ambientais ao sistema fluvial - uma revisão de conceitos. Caminhos de Geografia, Uberlândia, v. 14, n. 46, p. 224-233, 2013. 